\title{
CHARACTERISTICS OF ACUTE INTOXICATIONS WITH REGARD TO CAPACITY FOR EFFECTIVE DOCTOR- PATIENT COMMUNICATION AND COMPETENT INFORMED DECISIONS
}

\author{
Marieta Yovcheva-Stancheva ${ }^{1,2}$, Snezha Zlateva ${ }^{2,3}$, Ekaterina Borisova ${ }^{4}$ \\ ${ }^{1}$ Clinic of Toxicology, Naval Hospital, Varna, Military Medical Academy \\ ${ }^{2}$ Department of Pharmacology, Toxicology and Pharmacotherapy, Faculty of Pharmacy, \\ Medical University of Varna \\ ${ }^{3}$ Clinic of Intensive Treatment of Acute Intoxications and Toxicoallergies, \\ Naval Hospital, Varna, Military Medical Academy \\ ${ }^{4}$ Consultative Psychiatric Office, Naval Hospital, Varna, Military Medical Academy
}

\section{ABSTRACT}

INTRODUCTION: Altered mental status caused by certain acute poisonings creates barriers for effective doctor-patient communication and compromises the process of informed consent (IC) for treatment. A categorization of toxicological patients with regard to communication capacity would be helpful for practical purposes.

AIM: This article has the following aims:

$\diamond$ characterization of toxicology patients with mental status altered by poisoning according to the etiology of intoxication;

$\diamond$ discussion of the impact of cerebral toxic syndrome on the capacity for effective communication between the doctor and the patient and for IC.

MATERIALS AND METHODS: A retrospective study of the medical documentation of 2088 patients with acute intoxications, treated in the Clinic of Intensive Treatment of Acute Intoxications and Toxicoallergies at Naval Hospital, Varna during the 2010-2013 period: case files, IC forms, was conducted. The R program package, version 3.4.2 (2017-09-28), was used for statistics.

RESULTS: Toxic cerebral syndrome was found in 966 cases of acute intoxication, $46 \%$ of all patients, with especially high percentages in the medicament, alcohol, and narcotics intoxication groups. Regaining lucid mental state was observed within 1 hour in $21.9 \%$ of patients, and for the rest, it took from 2 hours to 7 days. Only 1211 patients, or $58 \%$, signed the admission IC form themselves.

Address for correspondence:

Marieta Yovcheva-Stancheva

Clinic of Intensive Treatment of Acute Intoxications and

Toxicoallergies

Naval Hospital, Varna

Military Medical Academy

3 Hristo Smirnenski Blvd

9002 Varna

e-mail:marietyovcheva@gmail.com

Received: November 23, 2020

Accepted: December 7, 2020
CONCLUSION: Characterization of acute intoxications with regard to capacity for effective doctorpatient communication is necessary because of the great percentage of patients with cerebrotoxic syndrome. Good knowledge of the specificity of toxicology patients and good communication skills of physicians can help the proper process of informed decisions of the patient.

Keywords: intoxication, cerebral toxic syndrome, effective communication, informed consent 


\section{INTRODUCTION}

The effective communication between the physician and the patient is one of the basic prerequisites for good-quality diagnostic and therapeutic results in medicine (1-5). Ideally, in an effective communication cycle, the information from the communicator-physician, is translated without any distortion to the recipient-patient, who then thinks it over carefully, in full consciousness, makes a decision, and sends it back to the communicator $(2,4,6,7)$. The ability of both communicating sides to receive and assimilate information, make decisions according to it, and send back information is of key importance for the quality of communication (2,5,9-12). There are different types of communication barriers in clinical medicine: physiological, psychological, cultural, environmental, organizational, semantic, and syntactic $(6,8,24,25)$. The first three types are most important in clinical toxicology.

There are few articles strictly discussing communication difficulties in toxicology, but a lot of the problems described in emergency medicine are valid for toxicology patients as well. The communication problems of clinical toxicology patients are part of the general communication problems of clinical medicine but have their own specificity. When there is toxic cerebral syndrome, specific communication barriers may arise at any stage of the intoxication; both in verbal and nonverbal communication (13-16). The founder of Bulgarian clinical toxicology, Prof. Monov, discussed this well-known characteristic of toxicology practice: "First, we see the capacity for contact with the patient. Between the obnubilation and the deep coma, a whole scale of impaired contact of the patients with the surrounding world exists, and it is expressed in their change of perception of the world and change in their behavior" (13).

Numerous communication factors are specific in toxicology cases:

\section{Factors related to the altered because of the intoxication mental status: \\ $\diamond$ frequently acute and sudden-onset temporary change in cognitive processes, as a result of ce- rebrotoxic syndrome, that leads to difficulty or impossibility of receiving and processing of in- formation and distorted and incorrect mental picture, ratiocination, and decisions;}

$\diamond$ intoxication-related or premorbid change of emotions;

$\diamond$ premorbid or intoxication-related change of the will processes, e.g. pathological obstinacy or apathy;

$\diamond$ frequently-dissimulation; rarely—simulation or aggravation;

$\diamond$ the initial history is often missing or distorted partially or totally by the patient or the relatives (11, 13-21).

II. Factors related to the patient but without direct connection to the intoxication:

$\diamond$ autoaggressive behavior at the present moment or in the past-suicide intentions and attempts, substance abuse or addiction;

$\diamond$ patients with negative attitude to medical help and hospital treatment;

$\diamond$ comorbidity—chronic or acute mental disease, serious physical disease;

$\diamond$ patients who have no knowledge about and/or experience with toxic substances and acute toxicology situations-children, patients with dementia, etc.;

$\diamond$ patients with social problems;

$\diamond$ patients with language barriers;

$\diamond$ patients who are afraid of the potential negative impact of the information about their intoxication on their family, professional, or social life.

All of these factors lead to frequent problems in the process of obtaining IC for treatment $(1,3,5,7-$ 10,22-25). They mainly affect the basic factor for IC-the patient's competency, and thus the informational components and consent components. A lot of problems exist from a legal viewpoint as well. The first rule of IC is that it must be "concrete, voluntary, in advance, and informed," so a valid IC requires an alert patient with preserved ability to give such consent $(1,12)$. An important feature of communication barriers and the related IC problems in patients with cerebrotoxic syndrome is that they are usually transitional and temporary $(13,15-18,20)$.

\section{AIM}

This article has the following aims:

$\diamond$ characterization of patients with altered because of acute poisoning mental status with regard to the etiology of the intoxication; 
$\diamond$ discussion of the impact of altered mental status on the capacity for effective communication between the physician and the patient and on the process of obtaining IC for treatment.

\section{MATERIALS AND METHODS}

A retrospective study of medical documentation-preliminary ambulatory consultation, hospital

\section{RESULTS}

There was a great variety in the etiology causes of acute intoxications during the studied period. Several etiological factors suggested high frequency of cerebral changes: ethanol and other alcohols, narcotics, part of the medicaments, part of the pesticides, carbon monoxide (Table 1).

Table 1. Toxic cerebral changes in different etiological groups of intoxication

\begin{tabular}{|c|c|c|c|c|c|}
\hline $\begin{array}{l}\text { Etiology of } \\
\text { Intoxication }\end{array}$ & $\begin{array}{l}\text { Total number } \\
\text { in Etiology } \\
\text { Subgroup }\end{array}$ & $\begin{array}{l}\text { Mind Changes } \\
\text { Due to Toxicity }\end{array}$ & $\begin{array}{c}\text { Percentage } \\
\text { of Cerebral } \\
\text { Toxicity in This } \\
\text { Subgroup }\end{array}$ & $\begin{array}{c}\text { Percentage } \\
\text { of Cerebral } \\
\text { Toxicity from } \\
\text { the Total } \\
\text { Number }\end{array}$ & $\begin{array}{l}\text { Conclusion About } \\
\text { Communication }\end{array}$ \\
\hline All intoxications & 2088 & 966 & $46.0 \%$ & $46.0 \%$ & highly impaired \\
\hline Medicaments & 436 & 316 & $72.5 \%$ & $15.0 \%$ & highly impaired \\
\hline Ethanol & 575 & 451 & $78.4 \%$ & $21.5 \%$ & highly impaired \\
\hline Methanol or EG & 41 & 32 & $78.0 \%$ & $1.5 \%$ & highly impaired \\
\hline Narcotics & 120 & 84 & $70.0 \%$ & $4.0 \%$ & hihgly impaired \\
\hline $\begin{array}{l}\mathrm{CO} \text { and fume } \\
\text { gases }\end{array}$ & 58 & 22 & $37.9 \%$ & $1.0 \%$ & $\begin{array}{l}\text { possible, with } \\
\text { problems }\end{array}$ \\
\hline $\begin{array}{l}\text { Household } \\
\text { products }\end{array}$ & 294 & 5 & $1.7 \%$ & $0.2 \%$ & $\begin{array}{l}\text { possible, rare } \\
\text { problems }\end{array}$ \\
\hline Organic solvents & 36 & 26 & $72.2 \%$ & $1.2 \%$ & highly impaired \\
\hline Pesticides & 45 & 27 & $60.0 \%$ & $1.3 \%$ & highly impaired \\
\hline $\begin{array}{l}\text { Plants and } \\
\text { animals }\end{array}$ & 483 & 3 & $0.6 \%$ & $0.1 \%$ & possible \\
\hline
\end{tabular}

files-history, physical examination, clinical course, discharge summary, and follow-up examination of 2088 patients with different kinds of intoxication treated in the Clinic of Intensive Treatment of Acute Intoxications and Toxicoallergies during the period of 2010-2013 was conducted. Twelve patients with pre-existing permanent dementia were excluded from the study. Assessment of the level of consciousness using the Reed scale and Glasgow Coma Scale (GCS) was done. The written IC for treatment at the admission of the same patients was analyzed. Statistical analysis with $\mathrm{R}$ program package, version 3.4 .2 (2017-09-28), with descriptive statistics, chi-square goodness-of-fit test and test of homogeneity, comparison of difference between two population proportions using Student's t-test, and correlation analysis were conducted.
A total of 966 patients, or $46 \%$ of the total number of patients, during the period had some form of quantitative or qualitative alteration of the mental status caused by intoxication.

The percentages of patients with preserved lucid mind and of those with cerebrotoxic syndrome were different in the different etiology groups. The highest percentage of cerebrotoxic syndrome was found in the group of ethanol intoxications -450 out of a total of 575 patients, or $78.2 \%$; medicament intoxications - 317 out of a total of 436 patients, or 72.7\%; narcotics-85 patients out of a total of 120 patients, or $70.8 \%$. A low percentage of cerebrotoxic changes was found in the groups of household poisonings-29 out of a total of 296 patients, or $9.8 \%$, and especially in the group of animal envenomations 
and plant poisonings -8 out of a total of 493 patients, or $1.6 \%$ (Fig. 1).

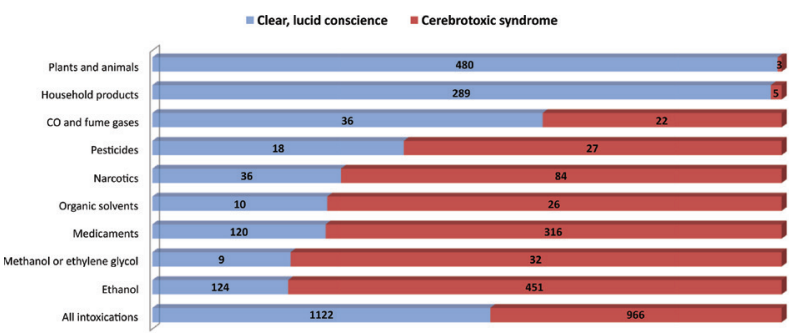

Fig. 1. Prevalence of cerebrotoxic changes in etiology subgroups $\diamond$ possible, effective communication when the physician has good communication skillsalert and responsive patients, including those with emotional instability-1134, or 53.8\%.

There was variety in the reported causes and motives for intoxication as well. Only 788 cases were accidental poisonings, or $37.7 \%$. In 440 cases, or $21.1 \%$, there was substance abuse, and in another 251 cases, or $12.0 \%$ - addiction to different chemical agents. A total of 609 cases, or $29.2 \%$, were suicide attempts (Table 3). In 97 cases of the suicidal poisonings, or $16 \%$, it was a second suicide attempt, and in

Table 2. Capacity of effective communication at admission according to the initial assessment of the mental status $(N=2088)$

\begin{tabular}{|c|c|c|}
\hline Possibility of Effective Communication & $\begin{array}{c}\text { Number of } \\
\text { Patients }\end{array}$ & Percentage \\
\hline $\begin{array}{l}\text { Possible communication when the communicator has good communication skills } \\
\quad \diamond \text { GCS } 13-15 \\
\diamond \text { Clear mind } \\
\diamond \text { Clear mind but with emotional instability }\end{array}$ & 1124 & $53.8 \%$ \\
\hline $\begin{array}{l}\text { Difficult comunication, unclear effectivity even in case of skilled communicator } \\
\text { GCS } 9 \text { - } 12 \\
\quad \diamond \text { Obnubilation } \\
\quad \diamond \text { Somnolence } \\
\diamond \text { Part of milder cases of psychomotor agitation }\end{array}$ & 649 & $31.1 \%$ \\
\hline $\begin{array}{l}\text { Impossible communication even in case of skilled communicator } \\
\quad \diamond \text { GCS } 8 \text { or less } \\
\quad \diamond \text { Coma } \\
\quad \diamond \text { Sopor } \\
\quad \diamond \text { Delirium } \\
\diamond \text { Severe cases of psychomotor agitation }\end{array}$ & 315 & $15.1 \%$ \\
\hline
\end{tabular}

The alterations of mental status caused by intoxications could be divided into 3 groups with regard to the capacity for effective communication ( $\mathrm{Ta}-$ ble 2):

$\diamond$ totally impossible communication-coma, sopor, delirium, and some of those with severe psychomotor agitation-315 patients, or $15.1 \%$;

$\diamond$ possible but difficult communication with unclear effectiveness, even when the physician has good communication skills-somnolence, obnubilation, milder psychomotor agitation-651 patients, or $31.1 \%$;
49 cases, or $8 \%$ - a third or further attempt.

Table 3. Reasons for acute intoxications

\begin{tabular}{lcc} 
Reasons for Intoxication & $\begin{array}{c}\text { Number of } \\
\text { Patients }\end{array}$ & Percentage \\
Accidental poisoning & 788 & $37.7 \%$ \\
Abuse & 440 & $21.1 \%$ \\
Addiction & 251 & $12.0 \%$ \\
Suicide attempt & 609 & $29.2 \%$ \\
Total number & 2088 & $100 \%$ \\
\hline$P<0.001$ at chi-square test of Pearson &
\end{tabular}


Table 4. Time of regaining lucid consciousness of patients with initial mental status altered by acute intoxication $(N=966)$

\begin{tabular}{lcc|c}
\hline $\begin{array}{l}\text { Regaining } \\
\text { Lucid } \\
\text { Consciousness }\end{array}$ & $\begin{array}{c}\text { Number } \\
\text { of } \\
\text { Patients }\end{array}$ & Percentage & Exponent \\
\hline $0-1$ hours & 212 & $21.9 \%$ & 20.5 \\
$2-3 \mathrm{~h}$ & 193 & $20.0 \%$ & 18.5 \\
$4-6 \mathrm{~h}$ & 165 & $17.1 \%$ & 16.4 \\
$7-9 \mathrm{~h}$ & 125 & $12.9 \%$ & 14.1 \\
$10-12 \mathrm{~h}$ & 87 & $9.0 \%$ & 12.1 \\
$13-24 \mathrm{~h}$ & 88 & $9.1 \%$ & 8.3 \\
$25-48 \mathrm{~h}$ & 39 & $4.0 \%$ & 3.4 \\
$49-72 \mathrm{~h}$ & 21 & $2.2 \%$ & 1.7 \\
Over 72 h & 19 & $2.0 \%$ & - \\
$\begin{array}{l}\text { Psycho-organic } \\
\text { state }\end{array}$ & 17 & $1.8 \%$ & - \\
\hline$X^{2}=1.48$ at d.f. $=7 ; p<0.05$ & &
\end{tabular}

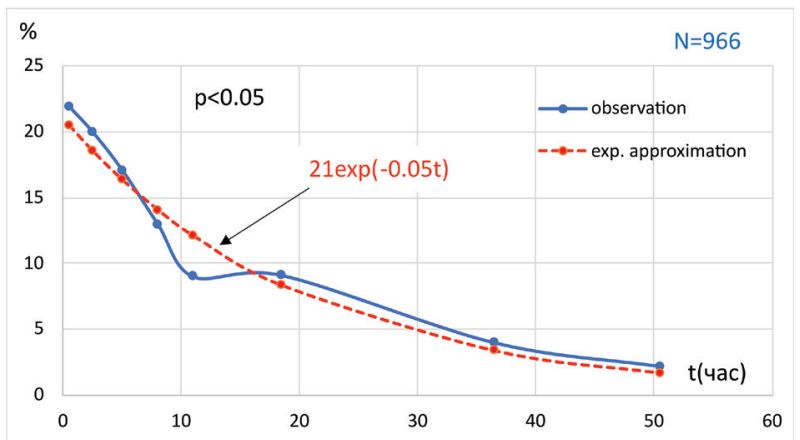

Fig. 2. Time of regaining lucid consciousness of patients with initial mental status altered by acute intoxication $(N=966)$

In cases of alteration of the mind because of intoxication, the initial mental status is changing dynamically during the next hours or days, so a dynamic assessment is necessary. Regaining of lucid mental state was observed within 1 hour in 212 cases, or $21.9 \%$, within 2 to 3 hours in 193 cases, or $20.0 \%$, and the in the rest of the cases-later than that. (Table 4, Fig. 2). Psychomotor agitation at some stage of the intoxication was observed in 343 cases, or $16.4 \%$ of all the patients.

The impaired communication between the patients with acute intoxications and the medics created problems in the process of obtaining IC for treatment and, particularly, in the signing of the admission IC form. The IC form was signed by the patient him/herself in only 1211 cases, or 58\%. In 670 cases, or $32 \%$, it was signed by relatives or official representatives of the patient, and in another 145 cases, or 7\%, it was signed by persons who were not relatives, i.e. friends or neighbors. Sixty-two hospital files did not contain a signed IC. They were mainly patients with acute ethanol intoxication who left the clinic willfully after regaining lucid mental state (Table 5).

A correlation analysis was conducted, which revealed a strong negative correlation between the percentages of patients with cerebrotoxic syndrome in each etiology group and the percentage of patients who have signed the admission IC form themselves (Table 6).

\section{DISCUSSION}

With the increase of global use of medicaments and other chemical compounds with cerebral toxic potential, the probability of acute intoxications caused by them has also increased. This creates a number of problems for the communication between the intoxicated patient and medical professionals, in addition to the specifically medical issues.

There was great variety in the capacity for effective communication in the group of toxicology patients studied during the observed period, which is a reflection of the great etiological variety of acute intoxications $(13,14,21)$. The key factor is the presence

Table 5. Initial signature on the informed consent (IC) form for treatment of patients with acute intoxications

\begin{tabular}{lcc|c|c|}
$\begin{array}{l}\text { Signature of the } \\
\text { Patient Himself/ } \\
\text { Herself }\end{array}$ & $\begin{array}{c}\text { Signature of } \\
\text { Relatives or Lawful } \\
\text { Representative }\end{array}$ & $\begin{array}{c}\text { Signature of Friend, } \\
\text { Neighbor, etc. }\end{array}$ & $\begin{array}{c}\text { No Signature on } \\
\text { IC-form }\end{array}$ & $\begin{array}{c}\text { Total Number of } \\
\text { Patients }\end{array}$ \\
\hline 1211 & 670 & 145 & 62 & 2088 \\
$58 \%$ & $32 \%$ & $7 \%$ & $3 \%$ & $100 \%$ \\
$\mathrm{P}<0.001$ & $\mathrm{P}<0.001$ & $\mathrm{P}<0.001$ & $\mathrm{P}<0.001$ & - \\
\hline
\end{tabular}


Characteristics of Acute Intoxications with Regard to Capacity for Effective Doctor-Patient Communication and Competent Informed...

Table 6. Correlation between cerebrotoxic syndrome and lack of capacity to sign the admission informed consent form

\begin{tabular}{l|ccccc} 
Etiology & $\begin{array}{c}\text { Total Number of } \\
\text { Patients in the } \\
\text { Group }\end{array}$ & $\begin{array}{c}\text { Patients with Toxic } \\
\text { Cerebral Syndrome in } \\
\text { the Group }\end{array}$ & $\%$ & $\begin{array}{c}\text { Number of Patients Who } \\
\text { Signed an IC Form for } \\
\text { Admission into Hospital } \\
\text { Themselves }\end{array}$ & $\%$ \\
$\begin{array}{l}\text { All intoxications } \\
\text { Medicaments }\end{array}$ & 2088 & 966 & 46.3 & 1211 & 58.0 \\
$\begin{array}{l}\text { Ethanol } \\
\begin{array}{l}\text { Methanol or } \\
\text { ethylene glycol }\end{array}\end{array}$ & 536 & 316 & 72.5 & 131 & 30.0 \\
$\begin{array}{l}\text { Narcotics } \\
\text { CO and fume }\end{array}$ & 120 & 451 & 78.4 & 175 & 30.4 \\
gases & 58 & 32 & 78.0 & 16 & 39.0 \\
$\begin{array}{l}\text { Household } \\
\text { products }\end{array}$ & 294 & 22 & 70.0 & 39 & 32.5 \\
$\begin{array}{l}\text { Organic solvents } \\
\text { Pesticides }\end{array}$ & 36 & 5 & 37.9 & 42 & 72.4 \\
$\begin{array}{l}\text { Plants and } \\
\text { animals }\end{array}$ & 45 & 26 & 1.7 & 284 & 96.6 \\
\hline
\end{tabular}

of cerebrotoxic syndrome, its gravity and dynamics $(13,18,20,21)$. A significant part $(46 \%)$ of all the patients admitted with acute intoxications had an altered mental status at the first consultation, which supposed serious potential communication difficulties. We assumed that the presence of toxic cerebral syndrome in more than $45-50 \%$ of the cases in any etiological group of acute intoxications indicates a highly impaired capacity for effective communication in this group. The percentage of initial cerebrotoxic syndrome was especially high in the groups of ethanol and other alcohols, medicament, narcotic and organic solvent intoxication. Very low percentage of cerebrotoxic changes was found in the groups of household poisonings and negligible-in animal and plant poisonings. The groups of pesticide poisonings and carbon monoxide intoxications were in the middle of this scale.

It is well known that when patients with deliberate intoxication are alert and responsive that does not mean that they are willing to communicate $(4,11,12,16,23)$. A great part of the studied group of patients had some form of self-harm: suicide attempt, abuse or addiction. Our results confirm an important characteristic of part of the patients with acute intoxication-high percentage of suicide attempts (13-14,23-25). Psychiatric assessment was done after admission in the hospital and regaining conscience. In this study we are only discussing communication difficulties which are created by an altered by intoxication mental status. When the medics have good communication skills and know well the specificity of toxicology patients, they can achieve effective communication with patients in lucid mind, even in cases of emotional instability $(1,2,4,8,9)$. The communication with patients with intoxication-related obnubilation, somnolence, or mild psychomotor agitation is usually possible but difficult and with uncertain effectiveness.

Cerebrotoxic symptoms are dynamic $(13,20)$. After the admission, the mental status can improve, worsen, or it can fluctuate. The time period of regaining a clear mind is different. In 212 cases out of 966 total, or $22 \%$, with initial toxic alteration of the mental status, it took up to 1 hour, and in the rest of the cases, it took from 2 hours to 72 hours. An exponential reduction of the number of the patients regaining lucid and clear consciousness in time was found, which confirms the necessity of a dynamic assessment of the mind in cases of intoxication. However, these results are for all acute intoxications, and great subgroup or individual variability is possible. The dynamics of consciousness of mixed intoxications and of cases with nontoxic cerebral comorbidi- 
Marieta Yovcheva-Stancheva, Snezha Zlateva, Ekaterina Borisova

ty are especially difficult to predict. The dynamics of cerebrotoxic symptoms in acute intoxication require a thorough individual assessment of the mental state by the treating physician and choice of the right moment for effective communication with the patient.

The alteration of mental status because of intoxication and its dynamics in the observed group affected the competency of the patient for informed decisions and had an impact on the process of obtaining IC and its written form. Only 1211 of the 2088 patients, or $58 \%$, signed IC forms at admission themselves. A very high negative correlation between the presence of some clinical form of cerebral toxicity and the capacity of the patient to sign the admission IC himself/herself was established for all acute intoxications during the studied period and also in the etiological subgroups. This confirms the need for further improvement of the process of IC with dynamic assessment of the consciousness and choosing the proper moment to communicate effectively.

A great part of the written forms of IC was signed by relatives or official representatives of the patient-670 IC, or $32 \%$. Less often, in $7 \%$, the IC was signed by another person who accompanied the patient at the admission (friends, neighbors, colleagues). According to the law, such IC is not valid if the patient does not also sign it later. In 63 files, or $3 \%$, no signed IC form was found, mainly patients with acute ethanol intoxication admitted in sopor or coma, who had left the clinic without informing the treating team after regaining consciousness. Such cases create legal problems and show the need of further improvement the communication with this particular group of patients $(1,3,5,12,23)$.

The results of the study of the IC written forms are a reflection mainly of the altered mental status and the inability of the patient to communicate effectively with the surrounding world, including with the physician. This inability can be expressed at the admission or later, at different stages of the intoxication $(16,25)$.

\section{CONCLUSION}

Characterization of the acute intoxications with regard to capacity for effective doctor-patient communication is necessary because of the great percentage of patients with cerebrotoxic syndrome. Good knowledge of the specificity of toxicology patients, dynamic assessment of the mental status, and good specific communication skills of the physicians and other medical specialists can help the proper process of the patient making informed decisions and, especially, obtaining IC for treatment.

\section{REFERENCES}

1. Valkanova M. Medical law. 1st ed. Varna, Bulgaria: Steno; 2014. (in Bulgarian).

2. Boncheva I. Medical psychology. 1st ed. Varna, Bulgaria: Steno; 2013. p. 89-129. (in Bulgarian).

3. Lisaev P. Medical deontology and medical law. Sofia, Bulgaria: Medicine and physical education; 2014. p. 9-89. (in Bulgarian).

4. Stoev V. Clinical communication. Sofia, Bulgaria: Softtrade; 2010. (in Bulgarian).

5. Jonsen AR, Siegler M, Winslade WJ. Clinical ethics: a practical approach to ethical decisions in clinical medicine. Introduction. (Ebook). 8th ed. New York, USA: McGraw-Hill Education; 2015.

6. Lipkin Jr. M, Schoenthaler A, Mohan V. Chapter 1. The medical interview. In: Feldman MD, Christensen JF, editors. Behavioral medicine: a guide for clinical practice. (Ebook). 4th ed. New York, USA: McGraw-Hill Education; 2014.

7. Radanov S. Medical deontology. Sofia, Bulgaria: Ciela; 2004. (in Bulgarian).

8. Eckerline CA, Shopp JD. I. Special aspects of emergency medicine. Chapter 5: Legal aspects of emergency care. Consent. In: Stone CK, Humphries RL, editors. Current diagnosis \& treatment: Emergency medicine. (Ebook). 8th ed. New York, USA: McGraw Hill Education; 2017.

9. Barstow C, Shahan B, Roberts M. Evaluating medical decision-making capacity in practice. Am Fam Physician. 2018;98(1):40-6.

10. Laponis R, Feldman MD. Section I: The doctor \& patient. Chapter 4. Difficult patients/difficult situations. In: Feldman MD, Christensen JM, Satterfield JM, Laponis R, editors. Behavioral medicine: a guide for clinical practice. (Ebook). 4 th ed. New York, USA: McGraw-Hill Education; 2014.

11. Stamenova P, Milanova M. Chapter 14. Consciousness. Attention. Altered mental status. In: Milanov I, editor. Neurology. Sofia, Bulgaria: Medicine and physical education; 2012. (in Bulgarian).

12. Zinovieva D. Medical law. 2nd ed. Sofia, Bulgaria: Ciela; 2016. p. 138-227. (in Bulgarian). 
Characteristics of Acute Intoxications with Regard to Capacity for Effective Doctor-Patient Communication and Competent Informed...

13. Monov A. Altered mental status with exogenous poisonings. In: Koychev K, editor. Comatose and syncopal states. 1st ed. Sofia, Bulgaria: Medicine and physical education; 1987. (in Bulgarian).

14. Marinov P. Acute intoxications - a contemporary view. 1st ed. Varna, Bulgaria: Steno; 2018. (in Bulgarian).

15. Simon RP, Aminoff MJ, Greenberg DA. Clinical neurology. Chapter 4, Confusional states. (Internet). 10th ed. McGraw-Hill Education; 2018 (cited 2018, Jul 25).

16. Yovcheva M. Deontological problems of clinical toxicology in Bulgaria, connected to communication difficulties, during the decade 2000-2010. J IMAB. 2012; 18(3):308-11.

17. Bedi G, Cecchi GA, Slezak DF, Carrillo F, Sigman $\mathrm{M}$, de Wit $\mathrm{H}$. A window into the intoxicated mind? Speech as an index of psychoactive drug effects. Neuropsychopharmacology. 2014; 39(10):2340-8. doi: 10.1038/npp.2014.80.

18. Berent S, Albers JW. Neurobehavioral toxicology neurological and neuropsychological perspectives. Volume I: Foundations and methods. 1st ed. London, UK: Taylor \& Francis; 2015.

19. Brust JSM. Section XVIII. Neurologic toxidromes. In: Merritt HH, Rowland LP, Louis ED, Mayer SA, editors. Merritt's neurology. 13th ed. Philadelphia, USA: Wolters Kluwer; 2016. p. 1074-89.

20. Harris JB, Blain PG. Neurotoxicology: what the neurologist needs to know. J Neurol Neurosurg Psychiatry. 2004; 75(Suppl 3):iii29-34. doi: 10.1136/ jnnp.2004.046318.
21. Popova M, Salovski P, Stoychev R, Aleksandrova M, Marev D, Ivanov D. Acute and chronic neurointoxications: clinical presentation, diagnostics, and treatment. Pleven, Bulgaria: Eurasia-Abagar; 1999. p. 6-38. (in Bulgarian).

22. Wachter RM, Gupta K. Understanding patient safety. Chapter 11. Other complications of healthcare. (Internet). 3rd ed. New York: McGraw-Hill Education; 2018 (cited 2018 Jul 30). Available from: http:// accessmedicine.mhmedical.com/content.aspx?boo kid=2203\&sectionid $=170435458$

23. Siff JE, Baskin BE. Section 26:Special situations. Chapter 303: Legal issues in emergency medicine. In: Tintinalli JE, Stapczynski JS, Ma OJ, Yealy DM, Meckler GD, Cline DM, editors. Tintinalli's emergency medicine: A comprehensive study guide. 8th ed. New York, USA: McGraw-Hill Education; 2015.

24. Mihaylova V, Liochkova M, Alakidi A, Kazandzhiev K, Shopov D. Forced interventions against persons with mental disorders - medical-legal accents. Trakia J Sci. 2018; 16(Suppl.1):110-6. doi:10.15547/tjs.2018.s.01.021.

25. Marco CA, Brenner JM, Kraus CK, McGrath NA, Derse AR, ACEP Ethics Committee. Refusal of emergency medical treatment: case studies and ethical foundations. Ann Emerg Med. 2017; 70(5):696703. doi: 10.1016/j.annemergmed.2017.04.015. 